\title{
The effect of low frequency and low intensity ultrasound combined with microbubbles on the sonoporation efficiency of MDA-MB-231 cells
}

\author{
Qi Liu, Jianwei Jiang, Lei Tang, Man Chen
}

Department of Ultrasound Medicine, Tongren Hospital, Shanghai Jiao Tong University School of Medicine, Shanghai 200336, China

Contributions: (I) Conception and design: Q Liu, J Jiang; (II) Administrative support: M Chen; (III) Provision of study materials or patients: None; (IV) Collection and assembly of data: Q Liu, J Jiang; (V) Data analysis and interpretation: Q Liu; (VI) Manuscript writing: All authors; (VII) Final approval of manuscript: All authors.

Correspondence to: Man Chen. Department of Ultrasound Medicine, Tongren Hospital, Shanghai Jiao Tong University School of Medicine, Shanghai 200336, China. Email: maggiech1221@126.com.

Background: Ultrasound can produce certain biophysical effects including thermal and non-thermal effects on cells. Sonoporation, the most widely studied non-thermal biological effect of ultrasound, is considered to be the basis for new therapeutic applications. Ultrasound irradiation can increase the permeability of cell membranes through sonoporous effect, which makes molecules like those of drugs, protein, and DNA that normally cannot pass through the cell membranes be able to enter cells. Considering the poor therapeutic effect and poor prognosis of triple negative breast cancer, we aimed to explore the experimental conditions and find the optimal parameters to improve the therapeutic efficacy of chemotherapeutic drugs for MDAMB-231 cells.

Methods: By establishing an experimental and control group, our study investigated the effect of low frequency and low intensity ultrasound combined with microbubbles on MDA-MB-231 cell membrane permeability at different times. We conducted factorial cross-design and set 3 levels of ultrasound intensity: 230, 300, and $370 \mathrm{~mW} / \mathrm{cm}^{2}$; 3 levels of irradiation time: 1, 2, and 3 minutes; and 6 levels of microbubble doses: 0, 0.2, 0.4, 0.6, 0.8, and $1 \mathrm{~mL}$.

Results: Results show that ultrasound intensity, time of irradiation, and microbubbles concentration are not only related to but also have interactive effects on the sonoporation efficiency of MDA-MB-231 cells, with the rank order being sound intensity, irradiation time, and microbubble concentration. The average positive rates (\%) of FD4 staining in sound intensities of 230,300 , and $370 \mathrm{~mW} / \mathrm{cm}^{2}$ levels were $1.20 \pm 0.71$, $13.80 \pm 5.86$, and $10.71 \pm 4.36$, respectively; and in irradiated times of 1,2 , and $3 \mathrm{~min}$ they were $7.54 \pm 5.95$, $9.74 \pm 8.42$, and $8.59 \pm 5.80$, respectively. When the microbubbles increased according to the gradient of 0 , $0.2,0.4,0.6,0.8$, and $1 \mathrm{~mL}$, the positive rates (\%) of FD4 staining were 7.32 $\pm 5.89,9.26 \pm 7.39,8.31 \pm 5.67$, $10.12 \pm 8.42,8.67 \pm 7.23$, and $7.72 \pm 6.24$.

Conclusions: In our study, the optimal parameters of the sonoporous effect for MDA-MB-231 cells were $300 \mathrm{~mW} / \mathrm{cm}^{2}$ of ultrasound intensity, 2 minutes of irradiation time, and $20 \%$ microbubbles concentration.

Keywords: MDA-MB-231; sonoporation; triple negative breast cancer; optimal parameters; in vitro experiment

Submitted Dec 31, 2019. Accepted for publication Feb 12, 2020.

doi: $10.21037 /$ atm.2020.02.155

View this article at: http://dx.doi.org/10.21037/atm.2020.02.155 


\section{Introduction}

Breast cancer remains the most common cancer among women worldwide and the leading cause of cancer death in women (1). Breast cancer has become one of the most important diseases that threaten women's quality of life and health. Based on histological features, breast cancer can be classified into 4 different molecular subtypes: luminal A, luminal B, HER2-overexpressing, and triplenegative breast cancer (TNBC). Different pathological types of breast cancer differ in clinical stage, lymph node metastasis, treatment, and prognosis. Although TNBC accounts for $10-17 \%$ (2) of all breast cancer pathological types in molecular typing, there are clinical features of it such as increased lymphocytic infiltration, aggressive metastatic behavior, and very poor prognosis (3). Due to its insensitivity to hormone therapy and targeted therapy, the treatment of TNBC is still a difficult problem for clinicians.

The experimental study of breast cancer cells in vitro has crucial clinical value. The biological effects of lowfrequency ultrasound irradiation combined with contrast agent microbubbles on breast cancer cells have attracted more and more attention and interest from researchers. The biophysical effects of ultrasound can be divided into thermal and non-thermal effects (4). The thermal effect of ultrasound involves tissue absorbing the energy transmitted by ultrasound to generate heat (5). The biological effects of ultrasound are usually produced by non-thermal mechanisms. Non-thermal effects include acoustic cavitation, acoustic radiation force, radiation torque, and acoustic streaming (5). Cavitation may be the most widely studied non-thermal mechanism of ultrasound and is considered the basis for new therapeutic applications.

Some studies have shown that ultrasound irradiation can increase the permeability of cell membranes through a sonoporous effect $(6,7)$, which makes drug, protein, and DNA molecules that normally cannot pass through the cell membranes, be able to enter cells. When using lower ultrasonic frequencies, the ultrasonic absorption coefficient is smaller, and the biological effects are mainly related to mechanical and cavitation effects (8). In addition, lowfrequency ultrasound irradiation can increase the number of cavitation nuclei in liquid media, reduce the threshold of cavitation, and enhance the cavitation effect in the presence of contrast microbubbles (9).

The efficiency of low-frequency ultrasound irradiation combined with microbubbles is affected by many parameters, such as irradiation power, microbubble concentration, and cell type (10). Many researchers have conducted relevant research in this area. For instance, Wang et al. (11) studied the effects of varied acoustic and microbubble-cell parameters on cell membrane permeability. In addition, tumor cell lines derived from di fferent tissues can impact the sonoporation efficiency (10). Ultrasound combined with microbubbles was also found to enhance the percentage of fluorescence-positive cells compared with control cells $(\mathrm{P}<0.05)(12)$. Qu et al.'s study indicated that different breast tumor cell lines have their own optimal sonoporation parameters (13). However, the frequency of ultrasound used in their study was $1 \mathrm{MHz}$, and the power of ultrasound irradiation was more than $500 \mathrm{~mW} / \mathrm{cm}^{2}$ of medium-energy ultrasound. With the increase of frequency and intensity of ultrasound irradiation, irreversible cell damage and mortality will increase.

In our study, we investigated the effect of low frequency and low intensity ultrasound combined with microbubble contrast agent irradiation on human triple negative breast cancer MDA-MB-231 cell membrane permeability at different times. We evaluated the correlation between the 3 factors (ultrasound intensity, contrast agent microbubble concentration, and irradiation time) and the sonoporous effect of MDA-MB-231 cells, so as to find the optimal combination of parameters for sonoporation efficiency of MDA-MB-231 cells irradiated by low frequency and low intensity ultrasound combined with microbubble contrast agent. According to this optimal combination of parameters, we assume that under this condition, the combination with paclitaxel drugs on 231 cells can improve the drug entry rate and the biological effects of ultrasound itself, so as to improve the efficacy of chemotherapy. It may also have potential significance for future research on triple negative breast cancer treatment.

\section{Methods}

\section{Cell culture}

The human TNBC cell line MDA-MB-231 was provided by the Oncology Laboratory of Tumor Hospital Affiliated to Medical College of Fudan University. MDA-MB-231 cells were maintained in RPMI-1640 (Gibco, USA) supplemented with $10 \%$ fetal bovine serum (FBS, Qualified, Australia Origin, USA) and $1 \%$ penicillin-streptomycin solutions. All cells were cultured in a humidified incubator at $37^{\circ} \mathrm{C}$ and $5 \%$ $\mathrm{CO}_{2}$, in standard cell culture flasks. All MDA-MB-231 cells used in the experiments were in the exponential phase. 
Table 1 Factors and levels of the experimental protocol

\begin{tabular}{lccc}
\hline \multicolumn{3}{c}{ Level } & \multicolumn{3}{c}{ Factors } \\
\cline { 2 - 4 } & $\begin{array}{c}\text { Sound intensity (a), } \\
\mathrm{mW} / \mathrm{cm}^{2}\end{array}$ & $\begin{array}{c}\text { Irradiation time } \\
\text { min }\end{array}$ & $\begin{array}{c}\text { Microbubble dose } \\
\text { (c), } \mathrm{mL}\end{array}$ \\
\hline 1 & 230 & 1 & 0 \\
2 & 300 & 2 & 0.2 \\
3 & 370 & 3 & 0.4 \\
4 & & & 0.6 \\
5 & & & 0.8 \\
6 & & & 1 \\
\hline
\end{tabular}

\section{Ultrasonic exposure}

Our research applied low-frequency and low-power ultrasonic cleaning machine (Dongsen, China) with a frequency of $40 \mathrm{kHz}$ and an adjustable ultrasonic power of 30 to $120 \mathrm{~W}$. The machine used piezoelectric transducer and non-focused acoustic wave. The inner groove size of the machine was $240 \times 135 \times 100 \mathrm{~mm}$, and the irradiation sound intensity could be adjusted from 100 to $370 \mathrm{~mW} / \mathrm{cm}^{2}$. A suitable amount of fresh distilled water preheated to $37{ }^{\circ} \mathrm{C}$ in advance was injected into the water tank. The sixhole plate with cell suspension was placed and fixed on the surface of the water. An ultrasound beam was emitted vertically up from the bottom of the tank. Distilled water could make the cell suspension exposed to more stable and uniform ultrasound irradiation in the tank.

\section{Ultrasound contrast agent and chemicals as a microbubble}

Experiments used SonoVue (Bracco Suisse SA, PlanLes-Ouates, Switzerland), a lipid shelled microbubble containing sulfur hexafluoride gas $\left(\mathrm{SF}_{6}\right)$, as a microbubble contrast agent. The microbubble was prepared by diluting the powder in $5 \mathrm{~mL}$ sterile $0.9 \%$ sodium chloride solution. Fluorescein isothiocyanate-dextran (FITC-dextran), as a fluorescent tracer, is often used to study the permeability of cell membranes in cardiovascular system, microcirculatory system, intestinal system and monolayer cells. We used FITC-Dextran4 (FD4, Sigma, USA) as a fluorescent tracer compound. We added $25 \mathrm{mg}$ FD4 to $1 \mathrm{~mL}$ phosphatebuffered saline (PBS), dissolved it fully, and stored it in a refrigerator at $4{ }^{\circ} \mathrm{C}$ to keep it away from light. Trypan blue is a cell reactive dye, which is often used to detect the integrity of cell membranes and the survival of cells. Living cells are not dyed blue, while dead cells are dyed light blue. Trypan Blue (0.4\%, liquid, sterile-filtered, Sigma, USA) was used in this study to detect cell viability.

\section{Experimental protocol}

The blank control group (no contrast agent, no ultrasound irradiation), the ultrasound irradiation group (no contrast agent, but placed in the ultrasound irradiation field), and the ultrasound irradiation combined with the microbubble group were established. MDA-MB-231 cells in the exponential growth phase were used for the irradiation experiment. We set 6 levels of microbubbles: $0,0.2,0.4,0.6,0.8$, and $1 \mathrm{~mL}$. The irradiation intensity was set at 230, 300, and $370 \mathrm{~mW} / \mathrm{cm}^{2}$, and the time was set at 1,2, and 3 minutes (Table 1), respectively. We regulated the 231-cell concentration to $>1 \times 10^{5} / \mathrm{mL}$, and then added $80 \mu \mathrm{L}$ FD4 (FITC-dextran 4) and 231 cell suspension of $2 \mathrm{~mL}$ into each pore of the sixhole plate. At last, $0,0.2,0.4,0.6,0.8$, and $1 \mathrm{~mL}$ microbubble contrast agents and $1,0.8,0.6,0.4,0.2$, and $0 \mathrm{~mL}$ PBS were added into each pore in turn. Microbubble dose, irradiation time, and acoustic intensity were adjusted to observe differences between the bioeffects demonstrated.

\section{Fluorescence positive rate and cell survival rate}

After irradiation, the cells are washed with PBS 3 times, and the entry of fluorescent reagent FD4 at different treatment levels was observed under the EVOSTM M5000 Imaging System (Thermo Fisher Science, USA). This imaging system can switch between the normal mode and fluorescent mode. Observation and photography were completed in fluorescence mode, and FD4 staining positive cells were seen in the cytoplasm with green fluorescence, and the total number of cells was saved and counted in the normal mode. The process of cell counting was carried out by using Image J software. Each group of experiment counts was repeated 3 times. Finally, the positive rate of fluorescence staining was calculated. The positive rate of fluorescence staining (\%) was calculated as follows: (the number of fluorescent positive cells/total cells) $\times 100 \%$. Next, $100 \mu \mathrm{L}$ irradiated cell suspension was stained with equivalent Trypan blue for 3 minutes and then dripped onto the cell counting board (Watson, Japan) for cell smear. Cytoplasmic and nuclear blue-stained cells were dead cells. The cell mortality at different treatment levels was calculated and recorded. Cell mortality (\%) was calculated as follows: (the number of blue-stained cells/total cells under microscope) $\times 100 \%$. 


\section{Statistical analysis}

The positive rate of FD4 staining and cell mortality were calculated by percentage, and expressed by mean \pm standard deviation $(\bar{\chi} \pm s)$. One-way analysis of variance (ANOVA) was used to compare the differences between different treatment groups. A P value $<0.05$ was considered statistically significant. SPSS 24.0 software was used for statistical analysis.

\section{Results}

\section{Microscopic results of cell fluorescence}

MDA-MB-231 cells cultured in vitro were adherent and grew in long spindle shapes. After digestion, the suspension cells were round or oval. The cell viability tested by Trypan blue was more than $95 \%$. After ultrasound irradiation, FD4 fluorescent positive cells showed bright green fluorescence in the fluorescence mode, while non-stained cells did not (Figure 1). The blank control group, ultrasound irradiation group, and ultrasound irradiation group combined with the microbubble group are shown in Figure 1: (A) without microbubbles and ultrasound irradiation; (B,C,D,E,F,G): irradiated by ultrasound $\left(370 \mathrm{~mW} / \mathrm{cm}^{2}, 1\right.$ minute) and with 0 , $0.2,0.4,0.6,0.8$, and $1 \mathrm{~mL}$ microbubbles added, respectively.

\section{Statistical analysis of cell survival rate in each group}

The viability of cells was observed under high power microscopy. Dead cells were dyed by Trypan blue into obvious blue or light blue, losing their normal round or elliptical shape, while living cells could not be dyed. Under the microscopy, living cells were bright, colorless, and transparent. Cell viability was counted at different treatment levels. As shown in Table 2, there was no significant difference in cell mortality among the different treatment levels of ultrasound irradiation power, time, and microbubble concentration $(\mathrm{P}>0.05)$.

\section{Statistical analysis of the difference of cell fluorescence positive rate among different groups}

The average fluorescence staining rates of cells at different treatment levels in each experimental group are shown in Table 3. The average positive rates (\%) of FD4 staining in irradiated sound intensity of 230,300 , and $370 \mathrm{~mW} / \mathrm{cm}^{2}$ levels were $1.20 \pm 0.71,13.80 \pm 5.86$, and $10.71 \pm 4.36$, respectively. The average positive rates (\%) of FD4 staining in irradiated times of 1,2 , and 3 min levels were $7.54 \pm 5.95$, $9.74 \pm 8.42$, and $8.59 \pm 5.80$, respectively. The positive rates
(\%) of FD4 staining in each level were 7.32 $\pm 5.89,9.26 \pm 7.39$, $8.31 \pm 5.67,10.12 \pm 8.42,8.67 \pm 7.23$, and $7.72 \pm 6.24$, when the microbubbles increased according to the gradient of $0,0.2,0.4,0.6,0.8$, and $1 \mathrm{~mL}$, respectively. Using oneway ANOVA and factorial design ANOVA, the positive rate of fluorescence staining in MDA-MB-231 was is correlated with ultrasound intensity, irradiation time, and microbubbles concentration $(\mathrm{P}<0.05)$. In addition, there was an interaction between any 2 of the 3 factors $(\mathrm{P}<0.05)$. Figure 2 shows the positive rate of fluorescence staining of cells at different levels of the 3 factors. When the irradiation time was 2 minutes, the overall positive rate of fluorescence staining was higher, with $300 \mathrm{~mW} / \mathrm{cm}^{2}$ irradiation intensity being the most obvious, while the positive rate of the 3 irradiation powers did not change much when the irradiation time was 1 or 3 minutes (Figure $2 A$ ). Figure $2 B$ shows that when the intensity of ultrasound irradiation was $230 \mathrm{~mW} / \mathrm{cm}^{2}$, the positive rate of fluorescence staining was relatively low and remained unchanged with the prolongation of irradiation time and the increase of microbubble concentration. When the intensity of ultrasound irradiation was $300 \mathrm{~mW} / \mathrm{cm}^{2}$, the positive rate of fluorescence staining was the highest when irradiated for 2 minutes. Figure $2 C$ shows the positive rate of fluorescence staining was the highest when the concentration gradient of the microbubbles was at the fourth level, especially when the ultrasound irradiation was $300 \mathrm{~mW} / \mathrm{cm}^{2}$ and the irradiation time was 2 minutes.

\section{Optimal parameter condition combination}

One-way ANOVA was used to analyze the effect of the other 2 factors on the positive rate of fluorescent staining when 1 of the 3 factors was fixed in turn. The significant results are shown in Figure 3. It can be seen that when the ultrasound intensity was $300 \mathrm{~mW} / \mathrm{cm}^{2}$, both irradiation time and microbubbles concentration had an effect on the positive rate of fluorescence $(\mathrm{P}<0.05)$, and there was an interaction between them $(\mathrm{P}<0.05)$; when the irradiation time was 2 minutes, both ultrasound intensity and microbubbles concentration had an effect on the positive rate of fluorescence $(\mathrm{P}<0.05)$, and there was an interaction between them $(\mathrm{P}<0.05)$; when adding $0.4 \mathrm{~mL}$ of microbubbles, both ultrasound intensity and irradiation time had an effect on the positive rate of fluorescence $(\mathrm{P}<0.05)$, and there was an interaction between them $(\mathrm{P}<0.05)$.

The positive rate of fluorescence at different sound intensities, when irradiation time was 2 minutes and $0.6 \mathrm{~mL}$ 

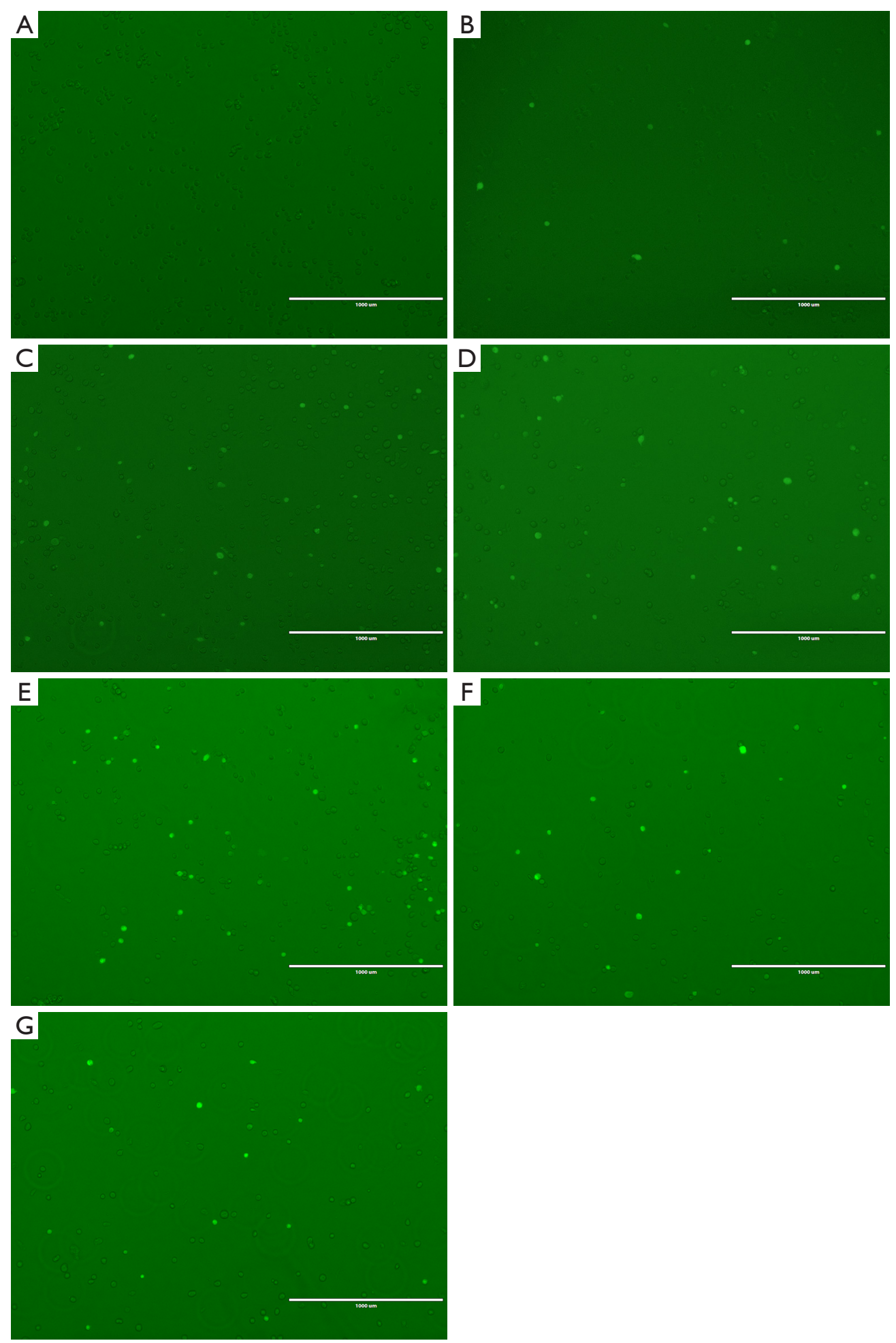

Figure 1 FD4 fluorescent positive cells showed bright green fluorescence in the fluorescence mode, while non-stained cells did not. Fluorescence staining results in the blank control group, ultrasound irradiation groups and ultrasound irradiation combined with microbubble group are shown in A,B,C,D,E,F,G: (A) fluorescence staining result in the blank control group that microbubbles and ultrasound irradiation are not added; (B,C,D,E,F,G): irradiated by ultrasound $\left(370 \mathrm{~mW} / \mathrm{cm}^{2}, 1 \mathrm{minute}\right)$ and $0,0.2,0.4,0.6,0.8$, and $1 \mathrm{~mL}$ microbubbles are added respectively. 
Table 2 Average cell mortality at different treatment levels in each experimental group

\begin{tabular}{llllll}
\hline Variables & $0 \mathrm{~mL}$ & $0.2 \mathrm{~mL}$ & $0.4 \mathrm{~mL}$ & $0.6 \mathrm{~mL}$ & $0.8 \mathrm{~mL}$ \\
\hline $230 \mathrm{~mW} / \mathrm{cm}^{2}$ & & & & $1 \mathrm{~mL}$ \\
$1 \mathrm{~min}$ & 0.0433 & 0.0459 & 0.0596 & 0.0601 & 0.0686 \\
$2 \mathrm{~min}$ & 0.0732 & 0.0865 & 0.0878 & 0.0952 & 0.1031 \\
$3 \mathrm{~min}$ & 0.0543 & 0.0670 & 0.0930 & 0.1043 & 0.0985 \\
$300 \mathrm{~mW} / \mathrm{cm}^{2}$ & & & & 0.1042 \\
$1 \mathrm{~min}$ & 0.0543 & 0.0911 & 0.0942 & 0.0897 & 0.1111 \\
$2 \mathrm{~min}$ & 0.0596 & 0.0558 & 0.0650 & 0.1014 & 0.1014 \\
$3 \mathrm{~min}$ & 0.0833 & 0.0929 & 0.0950 & 0.0971 & 0.1055 \\
$370 \mathrm{~mW} / \mathrm{cm}^{2}$ & & & & 0.0984 \\
$1 \mathrm{~min}$ & 0.0507 & 0.0654 & 0.0914 & 0.1073 \\
$2 \mathrm{~min}$ & 0.0786 & 0.0832 & 0.0921 & 0.0949 & 0.114 \\
$3 \mathrm{~min}$ & 0.0769 & 0.1150 & 0.1193 & 0.0893 & 0.1074 \\
\hline
\end{tabular}

Table 3 Average fluorescence staining rate of cells at different treatment levels in each experimental group

\begin{tabular}{|c|c|c|c|c|c|c|}
\hline Variables & $0 \mathrm{~mL}$ & $0.2 \mathrm{~mL}$ & $0.4 \mathrm{~mL}$ & $0.6 \mathrm{~mL}$ & $0.8 \mathrm{~mL}$ & $1 \mathrm{~mL}$ \\
\hline $1 \mathrm{~min}$ & 0.008021 & 0.008677 & 0.010309 & 0.010753 & 0.009412 & 0.006912 \\
\hline $2 \min$ & 0.009036 & 0.009050 & 0.013655 & 0.014388 & 0.008955 & 0.009221 \\
\hline $3 \mathrm{~min}$ & 0.011438 & 0.010540 & 0.011394 & 0.011896 & 0.010551 & 0.011594 \\
\hline $1 \mathrm{~min}$ & 0.060201 & 0.086124 & 0.085417 & 0.119005 & 0.085809 & 0.088180 \\
\hline $2 \min$ & 0.168443 & 0.188888 & 0.150341 & 0.275641 & 0.212318 & 0.195584 \\
\hline $3 \min$ & 0.119497 & 0.120787 & 0.126812 & 0.149733 & 0.105263 & 0.085809 \\
\hline \multicolumn{7}{|c|}{$370 \mathrm{~mW} / \mathrm{cm}^{2}$} \\
\hline $3 \mathrm{~min}$ & 0.141487 & 0.147132 & 0.140000 & 0.095685 & 0.109661 & 0.104110 \\
\hline
\end{tabular}

of microbubbles were added, is shown in Figure $4 A$; the positive rate of fluorescence at different irradiation times when ultrasound intensity and microbubbles were $300 \mathrm{~mW} / \mathrm{cm}^{2}$ and $0.6 \mathrm{~mL}$ respectively, is shown in Figure $4 B$; the positive rate of fluorescence at different microbubbles concentrations, when ultrasound intensity and irradiation time were $300 \mathrm{~mW} / \mathrm{cm}^{2}$ and 2 minutes respectively, is shown in Figure 4C. From the above statistical charts, it can be seen that when the power intensity of ultrasound irradiation was $300 \mathrm{~mW} / \mathrm{cm}^{2}$, the irradiation time was 2 minutes, and the concentration of microbubbles was $20 \%$ (adding $0.6 \mathrm{~mL}$ microbubbles), the positive rate of fluorescence staining (sonoporation efficiency) was the highest. That is, the combination possesses the optimal parameters of low frequency and low intensity ultrasound combined with microbubbles contrast agent irradiating MDA-MB-231 cells to produce acoustic pore effect. 

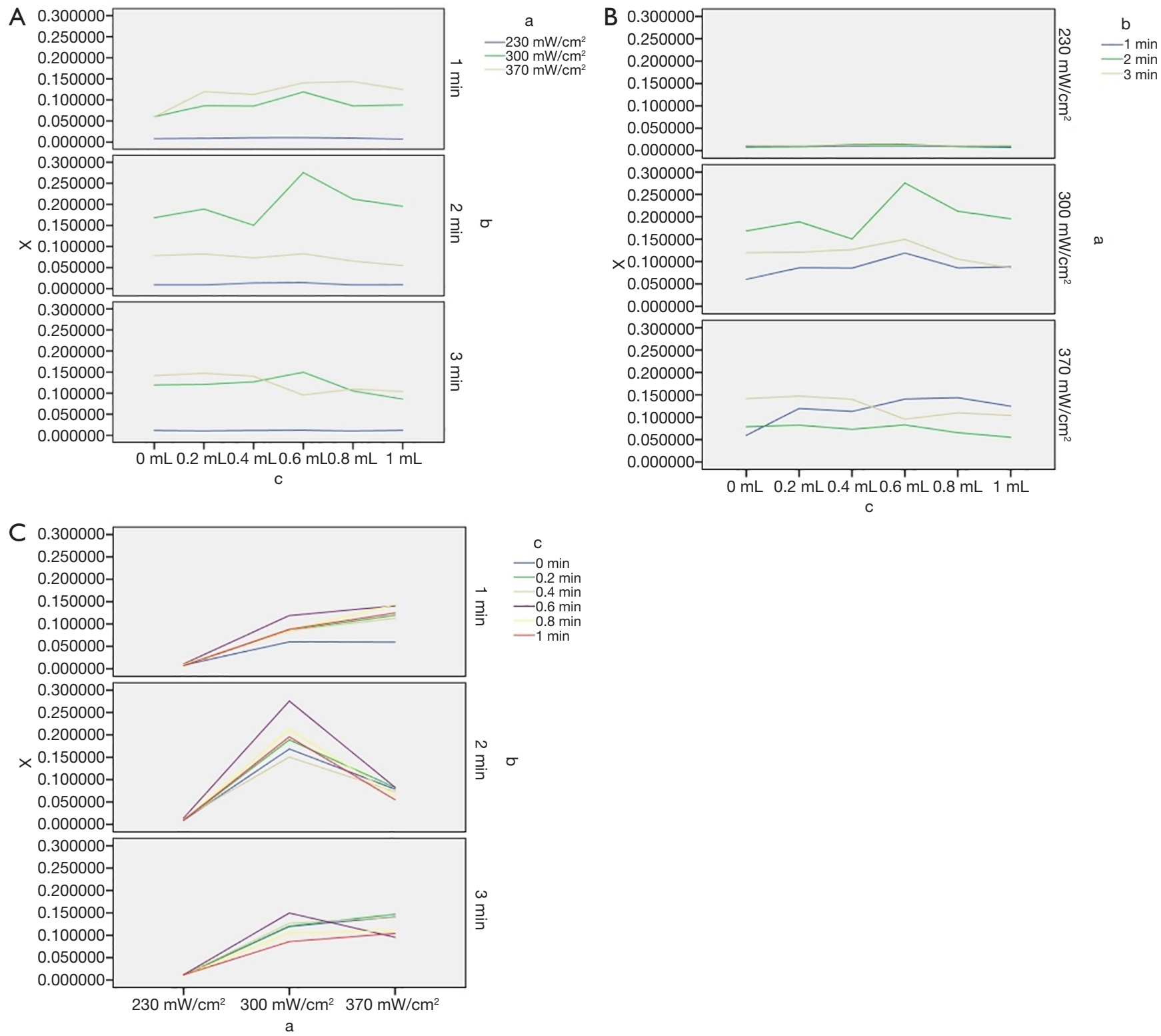

Figure 2 Positive rate of cell fluorescence staining at different levels of 3 factors: x-positive rate of fluorescence staining, (A) ultrasound intensity, (B) irradiation time, (C) microbubble dose.

\section{Discussion}

Early experimental studies have proposed and confirmed the acoustic perforation effect of ultrasound exposure on cells (14-16). An increasing number of scholars have used this effect to increase cell membrane permeability and transfer molecular substances into cells, including plasmids (17), genes (18), and drugs (19). In recent years, targeted drug delivery has garnered growing attention (20). Ultrasound-mediated drug delivery is efficient, safe, and controllable, and can improve the therapeutic efficacy of chemotherapeutic drugs for some cancer diseases. Our study focused on the clinical features of the poor therapeutic effect and poor prognosis in TNBC. In order to improve the therapeutic effect of followup ultrasound combined with microbubbles mediating chemotherapeutic drugs into TNBC cells, we established multi-factors and different levels and focused on exploring the optimal parameters of the sonoporation efficiency in 


\begin{tabular}{ccccc}
\hline Factors & Level & $\mathrm{b}$ & $\mathrm{c}$ & $\mathrm{b} \times \mathrm{c}$ \\
\hline \multirow{2}{*}{$\mathrm{a}$} & $230 \mathrm{~mW} / \mathrm{cm}^{2}$ & 0.680 & 0.419 & 0.803 \\
\cline { 2 - 5 } & $300 \mathrm{~mW} / \mathrm{cm}^{2}$ & 0.000 & 0.000 & 0.028 \\
\cline { 2 - 5 } & $370 \mathrm{~mW} / \mathrm{cm}^{2}$ & 0.000 & 0.396 & 0.242 \\
\hline Factors & Level & $\mathrm{a}$ & $\mathrm{c}$ & $\mathrm{a} \times \mathrm{c}$ \\
\hline $\mathrm{b}$ & $1 \mathrm{~min}$ & 0.000 & 0.066 & 0.507 \\
\cline { 2 - 5 } & $2 \mathrm{~min}$ & 0.000 & 0.001 & 0.000 \\
\hline Factors & $3 \mathrm{~min}$ & 0.000 & 0.058 & 0.051 \\
\hline $\mathrm{c}$ & Level & $\mathrm{a}$ & $\mathrm{b}$ & 0.000 \\
\cline { 2 - 5 } & $0.2 \mathrm{~mL}$ & 0.000 & 0.000 & 0.012 \\
\cline { 2 - 5 } & $0.2 \mathrm{~mL}$ & 0.000 & 0.904 & 0.009 \\
\cline { 2 - 5 } & $0.4 \mathrm{~mL}$ & 0.000 & 0.112 & 0.000 \\
\hline & $0.6 \mathrm{~mL}$ & 0.000 & 0.015 & 0.000 \\
\hline & $0.8 \mathrm{~mL}$ & 0.000 & 0.160 & 0.000 \\
\hline
\end{tabular}

Figure 3 Statistical analysis results (P values) of the 3 factors on the fluorescence staining positive rate respectively. a, ultrasound intensity; b, irradiation time; c, microbubble dose.

231 cells with in vitro experiments.

There have been many studies on the effects of lowfrequency ultrasound combined with microbubble contrast agent irradiation on cell membrane permeability (21-23), but there are few specific studies on human TNBC cell membrane permeability. This study has the following highlights and innovations. Firstly, low frequency $(40 \mathrm{kHz})$ and low intensity $\left(200-400 \mathrm{~mW} / \mathrm{cm}^{2}\right)$ ultrasound is used to produce a sonoporous effect. The low frequency biological effect is mainly related to the cavitation effect, and the thermal effect can be neglected. High intensity ultrasound is more likely to cause cell lysis (24), while low frequency and low intensity ultrasound are less harmful. Blue staining demonstrated the high survival rate of cells, and is conducive to the observation of cytoskeleton in subsequent experiments. Given that microbubbles are typically excited at a frequency within a certain range for therapeutic applications, some research $(23,25,26)$ usually use the frequency of $1-10 \mathrm{MHz}$ to observe the sonoporous effect. However, our results indicate that the lower frequency $(40 \mathrm{kHz})$ can also produce the sonoporous effect, and is likely able to observe the internal conditions of living cells in processes such as changes in microfilaments (27) and protein expression. Secondly, FD4 (average mol wt $3,000-5,000)$ was used as fluorescent reagent, while other researchers have used FD500 (average mol wt 500,000) in their study (10). The molecular weight of FD4 is smaller than FD500, so it is easier for FD4 to enter the cell (28) through the acoustic pore. Considering that the acoustic hole generated by ultrasound irradiation sometimes is not enough to allow FD500 to pass, this can be improved by using FD4 with a smaller molecular weight. Moreover, the molecular weight of FD4 is closer to that of paclitaxel (average mol wt 853.9) which is worth considering the for research using the sonoporous effect to promote the entry of paclitaxel into cells. Therefore, the fluorescence positive rate in our results can better reflect the sonoporation efficiency. Finally, based on the clinical characteristics of poor therapeutic effect and poor prognosis of TNBC, we used the human MDA-MB-231 cell line as the experimental object. Although the studies $(10,13)$ of $\mathrm{Qu} e t a l$. and Shi et al. explored sonoporation efficiency of breast cancer under ultrasound microbubble treatment, the ultrasound frequency and ultrasound intensity they used were $1 \mathrm{MHz}$ and more than $500 \mathrm{~mW} / \mathrm{cm}^{2}$ of medium-energy ultrasound. The MDA-MB-231 cell survival rate was no more than 78.98\% in Qu's study, and the cell survival rate of all groups in our study was more than $85.64 \%$. As ultrasound exposure frequency and intensity increase, irreversible cell damage and mortality also increase. Therefore, it is necessary to carry out multi-factor and multi-level experimental research at low frequency and low intensity to explore the optimal conditions for the sonoporous effect of 231 cells. We hope that this research can lay the foundation for the study of ultrasound combined with microbubbles to mediate the 

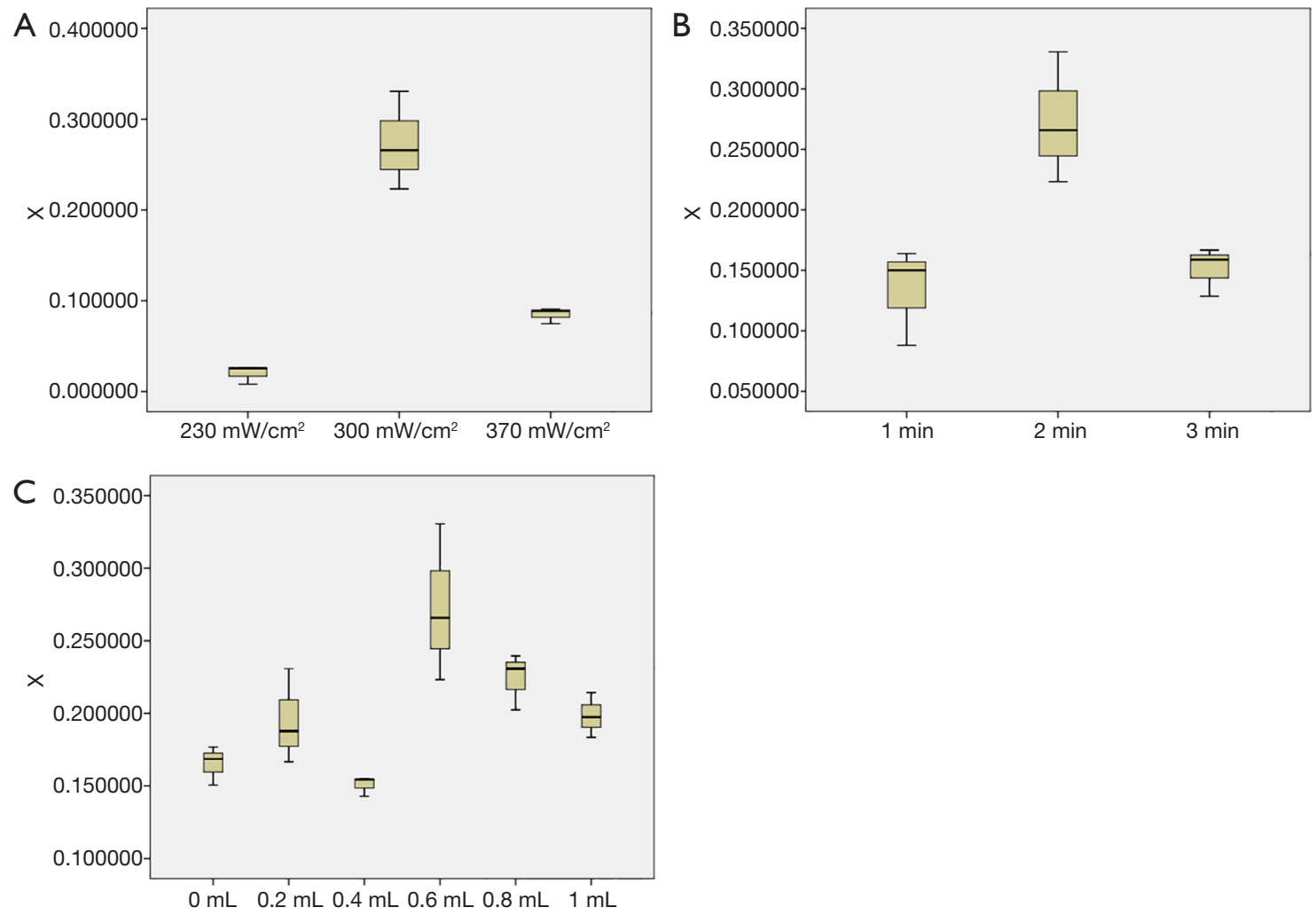

Figure 4 The optimal parameter combination of the 3 factors. (A) The positive rate of fluorescence at different sound intensities when the irradiation time was 2 minutes and $0.6 \mathrm{~mL}$ of microbubbles were added; (B) the positive rate of fluorescence at different irradiation times when the ultrasound intensity and microbubbles were $300 \mathrm{~mW} / \mathrm{cm}^{2}$ and $0.6 \mathrm{~mL}$ respectively; $(\mathrm{C})$ the positive rate of fluorescence at different microbubble concentrations when ultrasound intensity and irradiation time were $300 \mathrm{~mW} / \mathrm{cm}^{2}$ and 2 minutes respectively.

passage of chemotherapeutic drugs into 231 cells, which is expected to improve the therapeutic efficacy of TNBC.

Our results show that sound intensity, time of irradiation, and microbubble concentration are related to sonoporation efficiency. Additionally, the 3 factors have different and interactive effects on the sonoporous effect of MDAMB-231 cells. From the results of Figures 3,4, we can see the rank order of the 33 influential factors for MDAMB-231 cells are sound intensity, irradiation time, and microbubble concentration. In Qu's study (13), microbubble concentration was the main factor affecting the sonoporation efficiency of the MDA-MB-231 cell line, which might have been due to the application of different frequencies and intensity of sound irradiation. Figure $2 B$ shows that when the power of ultrasound irradiation was $230 \mathrm{~mW} / \mathrm{cm}^{2}$, the positive rate of fluorescence staining was low and remained unchanged with the prolongation of irradiation time and the increase of microbubble concentration. Figure $2 A$ shows that when the irradiation time was
2 minutes, the overall positive rate of fluorescence staining was higher, and the most obvious was a $230 \mathrm{~mW} / \mathrm{cm}^{2}$ ultrasound intensity. When the irradiation time is 1 or 3 minutes, the positive rate of 3 irradiation intensity does not change much. We can see from Figure $2 C$ that when the microbubbles concentration was $20 \%(0.6 \mathrm{~mL}$ of microbubbles), the positive rate of fluorescence staining was the highest, especially when the intensity of ultrasound was $300 \mathrm{~mW} / \mathrm{cm}^{2}$ and the irradiation time was 2 minutes.

Sonoporation efficiency will gradually increase with the enhancement of ultrasound intensity and irradiation time in a certain range $(29,30)$, which is also reflected in our experimental results. However, with the increase of sound intensity, the number of cavitation bubbles increases, which forms a gas barrier to prevent the propagation of sound waves outward (31), and increases the cell death rate. In addition, the prolongation of irradiation time can also lead to cell death, which Table 2 also shows. This might have been due to the prolongation of irradiation time, the increase of 
cavitation effect and cell damage, and the failure to repair cell membranes resulting in irreparable cell damage. The presence of microbubbles increases the number of cavitation nuclei in liquids, so the sonoporation efficiency increases in turn $(32,33)$. As the microbubble concentration increases, the sonoporation efficiency first increases and then decreases. This may be due to the increase of cavitation bubbles forming a gas barrier. We found the optimal parameters for the generation of sonoporous effect and confirmed the interaction of ultrasound intensity, irradiation time, and microbubble concentration.

Our research also has some limitations which should be addressed. Firstly, this experimental design adopts the common factorial cross-design, but does not use the orthogonal design method. The cross-design increases the number of experiments and the analysis workload of experimental data. Second, we used Image J software to calculate the number of sonoporated cells intercepted from multiple perspectives, which may not be as fast and accurate as flow cytometry. In Figure $4 C$, we can see that the fluorescence positive rate of group 3 was too low when $0.4 \mathrm{~mL}$ of microbubbles was added, which is inconsistent with the overall trend. This might have been caused by confounding factors and statistical calculation error.

In the future, we hope that low-frequency and lowintensity ultrasound combined with microbubble contrast agent irradiation can improve the efficacy of drug chemotherapy in vivo breast cancer tissue. The human body is a unified and complex organic whole. We will explore the mechanism of the sonoporous effect produced by ultrasound irradiation in human tissues and the factors that may influence this process. Many in vivo and in vitro experiments are still needed for the results to be applied to in vitro experiments in human models.

\section{Conclusions}

Human MDA-MB-231 cells irradiated by low-frequency and low-intensity ultrasound combined with microbubbles contrast agent can produce a sonoporous effect. The positive rate of fluorescence staining is related to the intensity of ultrasound, irradiation time, and concentration of microbubbles, and is most affected by the intensity of ultrasound power. In a certain range, the positive rate of fluorescence staining increases first and then decreases with the increase of ultrasound power intensity, irradiation time, and microbubble concentration. In the results of this study, when the power intensity of ultrasound, irradiation time, and the concentration of microbubbles were $300 \mathrm{~mW} / \mathrm{cm}^{2}$,
2 minutes, and $20 \%$ respectively, the positive rate of fluorescence staining was the highest. In other words, these were the optimal parameters for the sonoporous effect of MDA-MB-231 cells irradiated by low-frequency and lowintensity ultrasound combined with microbubbles.

\section{Acknowledgments}

Funding: This work was supported by the Natural Science Foundation of Shanghai (No. 18ZR1434800).

\section{Footnote}

Conflicts of Interest: The authors have no conflicts of interest to declare.

Ethical Statement: The authors are accountable for all aspects of the work in ensuring that questions related to the accuracy or integrity of any part of the work are appropriately investigated and resolved.

Open Access Statement: This is an Open Access article distributed in accordance with the Creative Commons Attribution-NonCommercial-NoDerivs 4.0 International License (CC BY-NC-ND 4.0), which permits the noncommercial replication and distribution of the article with the strict proviso that no changes or edits are made and the original work is properly cited (including links to both the formal publication through the relevant DOI and the license). See: https://creativecommons.org/licenses/by-nc-nd/4.0/.

\section{References}

1. Bray F, Ferlay J, Soerjomataram I, et al. Global cancer statistics 2018: GLOBOCAN estimates of incidence and mortality worldwide for 36 cancers in 185 countries. CA Cancer J Clin 2018;68:394-424.

2. Wang C, Kar S, Lai X, et al. Triple negative breast cancer in Asia: An insider's view. Cancer Treat Rev 2018;62:29-38.

3. Yao H, He G, Yan S, et al. Triple-negative breast cancer: is there a treatment on the horizon? Oncotarget 2017;8:1913-24.

4. Izadifar Z, Babyn P, Chapman D. Mechanical and Biological Effects of Ultrasound: A Review of Present Knowledge. Ultrasound Med Biol 2017;43:1085-104.

5. Dalecki D. Mechanical bioeffects of ultrasound. Annu Rev Biomed Eng 2004;6:229-48.

6. Kooiman K, Vos HJ, Versluis M, et al. Acoustic behavior 
of microbubbles and implications for drug delivery. Adv Drug Deliv Rev 2014;72:28-48.

7. Lammertink B, Deckers R, Storm G, et al. Duration of ultrasound-mediated enhanced plasma membrane permeability. Int J Pharm 2015;482:92-8.

8. Wei $W$, Zheng-zhong B, Yong-jie $W$, et al. Bioeffects of low-frequency ultrasonic gene delivery and safety on cell membrane permeability control. J Ultrasound Med 2004;23:1569-82.

9. Ultrasound. Nonthermal issues: cavitation--its nature, detection and measurement. Ultrasound Med Biol 1998;24 Suppl 1:S11-21.

10. Shi D, Guo L, Duan S, et al. Influence of tumor cell lines derived from different tissue on sonoporation efficiency under ultrasound microbubble treatment. Ultrason Sonochem 2017;38:598-603.

11. Wang M, Zhang Y, Cai C, et al. Sonoporation-induced cell membrane permeabilization and cytoskeleton disassembly at varied acoustic and microbubble-cell parameters. Sci Rep 2018;8:3885.

12. Wang Y, Bai WK, Shen E, et al. Sonoporation by low-frequency and low-power ultrasound enhances chemotherapeutic efficacy in prostate cancer cells in vitro. Oncol Lett 2013;6:495-8.

13. Qu N, Shi D, Shang M, et al. Breast Cancer Cell Line Phenotype Affects Sonoporation Efficiency Under Optimal Ultrasound Microbubble Conditions. Med Sci Monit 2018;24:9054-62.

14. Miller DL, Williams AR, Morris JE, et al. Sonoporation of erythrocytes by lithotripter shockwaves in vitro. Ultrasonics 1998;36:947-52.

15. Miller DL. A review of the ultrasonic bioeffects of microsonation, gas-body activation, and related cavitationlike phenomena. Ultrasound Med Biol 1987;13:443-70.

16. Lentacker I, De Cock I, Deckers R, et al. Understanding ultrasound induced sonoporation: definitions and underlying mechanisms. Adv Drug Deliv Rev 2014;72:49-64.

17. Bao S, Thrall BD, Miller DL. Transfection of a reporter plasmid into cultured cells by sonoporation in vitro. Ultrasound Med Biol 1997;23:953-9.

18. Kalli C, Teoh WC, Leen E. Introduction of genes via sonoporation and electroporation. Adv Exp Med Biol 2014;818:231-54.

19. Sennoga CA, Kanbar E, Auboire L, et al. Microbubblemediated ultrasound drug-delivery and therapeutic monitoring. Expert Opin Drug Deliv 2017;14:1031-43.

20. Wang LY, Zheng SS. Advances in low-frequency ultrasound combined with microbubbles in targeted tumor therapy. J Zhejiang Univ Sci B 2019;20:291-9.

21. Zhou Y, Yang K, Cui J, et al. Controlled permeation of cell membrane by single bubble acoustic cavitation. J Control Release 2012;157:103-11.

22. Watanabe $\mathrm{Y}$, Aoi A, Horie S, et al. Low-intensity ultrasound and microbubbles enhance the antitumor effect of cisplatin. Cancer Sci 2008;99:2525-31.

23. Escoffre JM, Novell A, Piron J, et al. Microbubble attenuation and destruction: are they involved in sonoporation efficiency? IEEE Trans Ultrason Ferroelectr Freq Control 2013;60:46-52.

24. Phenix CP, Togtema M, Pichardo S, et al. High intensity focused ultrasound technology, its scope and applications in therapy and drug delivery. J Pharm Pharm Sci 2014;17:136-53.

25. Escoffre JM, Piron J, Novell A, et al. Doxorubicin delivery into tumor cells with ultrasound and microbubbles. Mol Pharm 2011;8:799-806.

26. Tran TA, Roger S, Le Guennec JY, et al. Effect of ultrasoundactivated microbubbles on the cell electrophysiological properties. Ultrasound Med Biol 2007;33:158-63.

27. Chen X, Leow RS, Hu Y, et al. Single-site sonoporation disrupts actin cytoskeleton organization. J R Soc Interface 2014;11:20140071.

28. Bhutto DF, Murphy EM, Priddy MC, et al. Effect of Molecular Weight on Sonoporation-Mediated Uptake in Human Cells. Ultrasound Med Biol 2018;44:2662-72.

29. Miller DL, Quddus J. Sonoporation of monolayer cells by diagnostic ultrasound activation of contrast-agent gas bodies. Ultrasound Med Biol 2000;26:661-7.

30. Domenici F, Brasili F, Giantulli S, et al. Differential effects on membrane permeability and viability of human keratinocyte cells undergoing very low intensity megasonic fields. Sci Rep 2017;7:16536.

31. Hosseini SH, Zheng X, Vaezy S. Effects of gas pockets on high-intensity focused ultrasound field. IEEE Trans Ultrason Ferroelectr Freq Control 2011;58:1203-10.

32. Ward M, Wu J, Chiu JF. Ultrasound-induced cell lysis and sonoporation enhanced by contrast agents. J Acoust Soc Am 1999;105:2951-7.

33. Bouakaz A, Zeghimi A, Doinikov AA. Sonoporation: Concept and Mechanisms. Adv Exp Med Biol 2016;880:175-89.

Cite this article as: Liu Q, Jiang J, Tang L, Chen M. The effect of low frequency and low intensity ultrasound combined with microbubbles on the sonoporation efficiency of MDAMB-231 cells. Ann Transl Med 2020;8(6):298. doi: 10.21037/ atm.2020.02.155 